\title{
Descrições de duas espécies novas de Amblycerus Thunberg (Coleoptera, Bruchidae) ${ }^{1}$
}

\section{Cibele S. Ribeiro-Costa ${ }^{2}$}

\begin{abstract}
Descriptions of two new species of Amblycerus Thunberg (Coleoptera, Bruchidae). The following new species are described and illustrated: $A$. crassipunctatus sp.n. from Venezuela (Bolivar) and Brazil (Distrito Federal), and $A$. taeniopygus sp.n. from Brazil (Mato Grosso).

KEY WORDS. Coleoptera, Bruchidae, Amblycerus, taxonomy
\end{abstract}

As espécies de Amblycerus Thunberg, 1815, principalmente as do Brasil, tem sido descritas nos últimos anos (RIBEIRO-CosTA 1997, 1999) para posterior utilização em análises taxonômicas e definição de grupos de espécies. As provenientes dos Estados Unidos e México foram estudadas por ROMERo et al. (1996), resultando no estabelecimento de 15 grupos de espécies.

O presente trabalho tem como objetivo descrever Amblycerus crassipunctatus sp.n., que vem sendo utilizada em estudos ecológicos na Venezuela pelos pesquisadores Elena Raimundez, Jesus Romero Napoles e Clarence Dan Johnson. Descreve-se também outra espécie brasileira, Amblycerus taeniopygus sp.n., que compartilha com A. crassipunctatus sp.n., dentre outros caracteres, a presença de linha vertical mediana de pilosidade adensada no pigídio, dentre outros caracteres.

A metodologia utilizada nas descrições segue àquela descrita em RIBEIROCosta (1997).

\section{Amblycerus crassipunctatus sp.n.}

Figs $1-9$

Dimensões. Comprimento $6,00-7,75 \mathrm{~mm}(\mathrm{x}=6,75 \mathrm{~mm} ; \mathrm{n}=10)$; largura 3,33 $4,58 \mathrm{~mm}(\mathrm{x}=4,00 \mathrm{~mm} ; \mathrm{n}=10)$.

Tegumento. Coloração geral, testácea (Fig. 1).

Pilosidade. Cabeça com exceção de duas áreas glabras na região do sulco marginal, escutelo, apêndices, região ventral do corpo e pigídio com pilosidade flava; no escutelo geralmente pêlos adensados e no pigídio adensados em linha vertical mediana (Fig. 1). Pronoto fulvo com duas pequenas manchas medianas e, algumas vezes, com linha mediana discreta (Fig. 1). Élitros inteiramente fulvos (Fig. 1), raramente com pêlos flavos distribuídos em linha junto às bordas das inter-estrias.

1) Contribuição número 1097 do Departamento de Zoologia, Universidade Federal do Paraná.

2) Departamento de Zoologia, Universidade Federal do Paraná. Caixa Postal 19020, 81531-990 Curitiba, Paraná, Brasil. Bolsista do CNPq.

E-mail:stra@bio.ufpr.br 


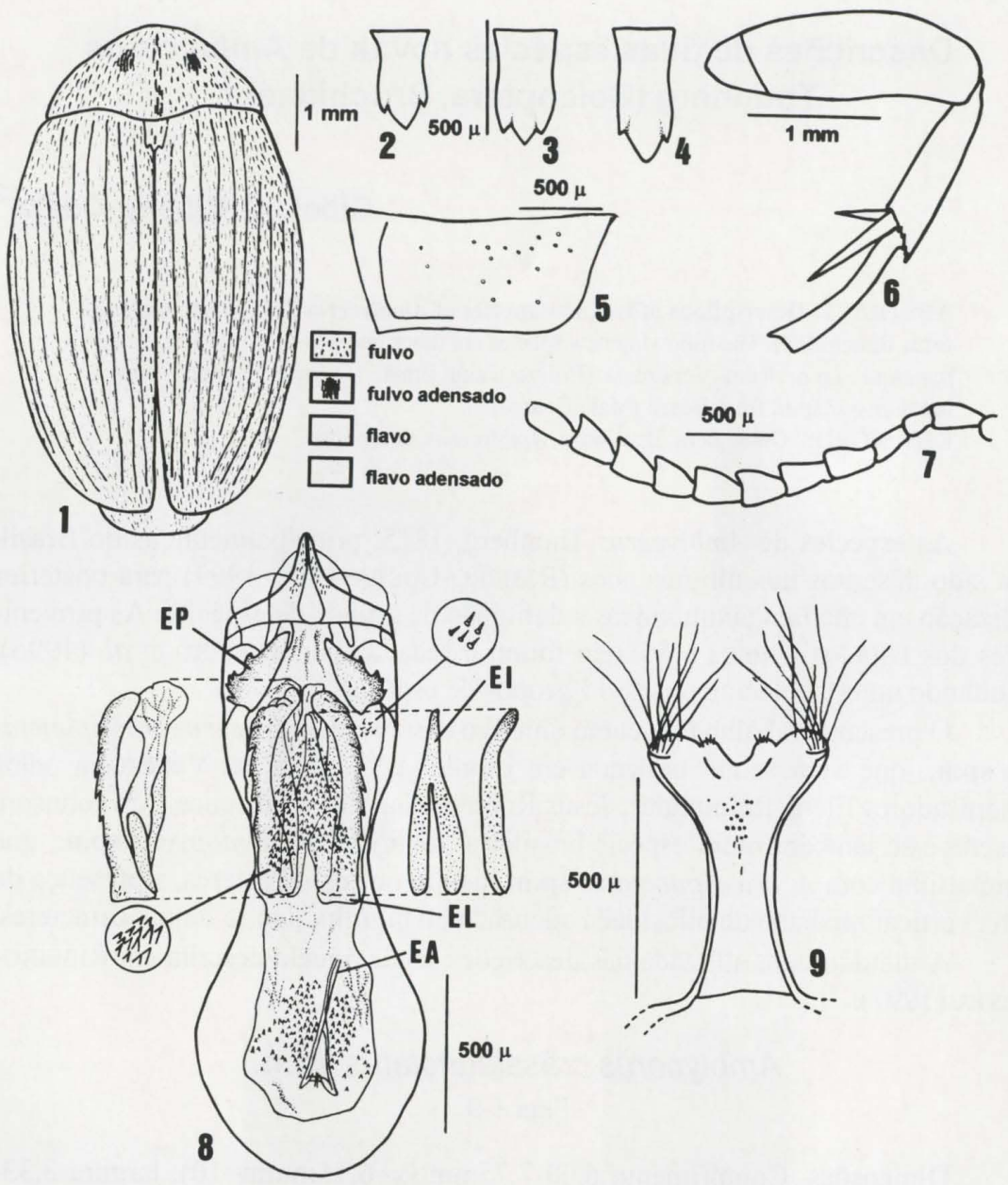

Figs 1-9. Amblycerus crassipunctatus sp.n.. (1) Padrão de coloração no dorso; (2-4) escutelo; (5) metepisterno; (6) perna posterior; (7) antena; (8-9) terminália do macho: (8) lobo médio; (9) tégmen.

Fronte levemente achatada. Olhos grandes, grossamente facetados, protraídos lateralmente; índice ocular 3,5; sinus ocular 1/4,6 o diâmetro do olho; lobo pós-ocular estreito, 1/11,4 vezes o maior comprimento do olho em vista lateral. Antena (Fig. 7) serreada a partir do quarto artículo; oitavo, nono e décimo artículos cerca de 1,3 vezes tão longos quanto largos; último artículo subelíptico. Pronoto trapezoidal com margens laterais levemente arqueadas em vista dorsal; pontos grossos levemente adensados e distribuídos em toda a superfície além da pontuação fina de fundo; sulco cervical presente nos $1 / 3$ laterais e com sulco em parte do bordo posterior; carena lateral não bifurcada anteriormente, muito além da metade do 
comprimento do pronoto, lateralmente. Processo prosternal largo, moderadamente expandido além das coxas anteriores. Escutelo cerca de 2,0 a 2,5 vezes tão longo quanto largo, com ápice tridentado, o dente mediano geralmente mais alongado e com ápice agudo (Figs 2-4). Élitros em corte transversal convexos ao longo da sutura, subtruncados apicalmente e com estrias fortemente impressas. Metepisterno (Fig. 5) com pontos grossos levemente adensados; eixo transversal do sulco metepisternal divergindo dorsalmente, eixo longitudinal aproximadamente a metade ou menos que a metade do comprimento do metepisterno; sem área estriada. Metasterno lateralmente sem pontos grossos. Coxas anteriores aparentemente no mesmo nível que as médias em vista lateral. Coxa posterior nos $2 / 3$ laterais com pontos grossos distribuídos mais centralmente. Fêmur posterior (Fig. 6) cerca de 2,7 vezes tão longo quanto largo; porção distal da face ventral não denteada. Tíbia posterior (Fig. 6) com espinhos coronais aproximadamente do mesmo tamanho, com linha de pontos e cerdas grossas conspícuas na face lateral; face ventral convexa com linha de pontos e cerdas grossas inconspícuas nas margens; esporão lateral o dobro do comprimento do mediano; o primeiro artículo tarsal posterior cerca de 1,5 vezes vezes tão longo quanto o esporão lateral e cerca de 3,0 vezes o esporão mediano. Pigídio do macho e da fêmea em forte declive em vista lateral; arredondado apicalmente. Quinto esternito visível suavemente emarginado no macho e na fêmea.

Terminália do macho (Figs 8-9). Oitavo tergito arredondado ou levemente emarginado apicalmente. Lobo médio (Fig. 8) com comprimento 3,7 vezes a sua maior largura na região basal; valva ventral curta com margens laterais fortemente côncavas, ápice afilado; valva dorsal subovalada com margens laterais moderadamente convexas, ápice arredondado. Região basal do saco interno sem escleritos anteriores e médios; um par de escleritos posteriores (Fig. 8EP) subtriangulares com quatro a cinco dentes na margem. Região mediana do saco interno com um par de escleritos laminares (Fig. 8EL), levemente arqueados, serreados na margem até os $3 / 4$ do seu comprimento, dentes aproximados; um esclerito ímpar (Fig. 8EI) em forma de forquilha, cerca de 0,8 vezes o comprimento dos laminares. Na região apical do saco interno um esclerito com hastes longas gradualmente convergentes (Fig. 8EA). Região basal e mediana do saco interno com vários espinhos curtos, e na região mediana, com vários dentículos adensados formando uma área central subtriangular. Tégmen (Fig. 9) com emarginação moderada, arredondada, entre os alargados lobos laterais.

Discussão taxonômica. Em A. taeniopygus sp.n.

Material-tipo. Holótipo macho. BRASIL, Distrito Federal: Brasília, VIII/97, F. Ramos leg. e, mais 21 parátipos, dois da VenEzuelA, Bolivar: Gran Sabana (Arbustal Riwo, riwo, via Kavanayen), VIII.93, E. Raimundez leg.; 19 parátipos do BRAsIL, Pará: Aldeia Coraci (11 Km W Canindé, Rio Gurupi), XII.964, B. Malkin leg. [1 ex.]; Mato Grosso: Barra do Tapirapé, 2-16.I.1966, B. Malkin leg. [4 ex.]; Três Lagoas (Faz. Dr. José Mendes) 15.VI.1964, Exp. Depto. Zool. leg. [1ex.]; Chapada dos Guimarães, 31.I.1961, J. \& B. Bechyné leg. [1ex.]; Minas Gerais: Lagoa Santa, 26.XI.960, Araújo e Martins leg. [2 ex.]; Paraopeba, sem data, E.P. Heringer leg. [9 ex.]; um exemplar do BRASIL, sem localidade, L.J. Bottimer Collection no. 61C. 
O holótipo e um parátipo depositados na Coleção de Entomologia Pe. Jesus S. Moure (Curitiba) (DZUP), sete parátipos no Museu de Zoologia, Universidade de São Paulo (São Paulo) (MZSP), um no Museu Paraense Emílio Goeldi (Belém) (MPEG), nove na Fundação Instituto Oswaldo Cruz (Rio de Janeiro) (FIOC), um no National Museum of Natural History (Washington) (NMNH) e dois na C.D. Johnson Collection (Flagstaff) (CDJ).

Etimologia. O nome da espécie refere-se a presença de pontos grossos distribuídos por todo o pronoto.

\section{Amblycerus taeniopygus sp.n.}

Figs 10-12

A descrição de $A$. taeniopygus sp.n. é semelhante a de $A$. crassipunctatus sp.n. exceto pelos seguintes caracteres:

Dimensões. Comprimento 5,58mm; largura 3,33mm.

Pilosidade. Pronoto sem manchas de pêlos adensados e, nos élitros, apenas pilosidade fulva.

Índice ocular 3,35; sinus ocular $1 / 4,0$ o diâmetro do olho; lobo pós-ocular $1 / 11,2$ vezes o maior comprimento do olho em vista lateral. Oitavo, nono e décimo artículos antenais cerca de 1,4 vezes tão longos quanto largos. Pronoto com pontos grossos apenas nos terços laterais além da pontuação fina de fundo. Processo prosternal levemente expandido além das coxas anteriores. Escutelo cerca de 2,2 vezes tão longo quanto largo, o dente mediano com ápice mais arredondado (Fig. 10). Metepisterno com pontos grossos esparsos; eixo transversal do sulco metepisternal quase reto dorsalmente; eixo longitudinal longo, além da metade do comprimento do metepisterno. Fêmur posterior cerca de 2,6 tão longo quanto largo. Tíbia posterior com esporão lateral cerca de 2,1 vezes o comprimento do mediano; o primeiro artículo tarsal posterior cerca de 1,5 vezes tão longo quanto o esporão lateral e cerca de 2,8 vezes o esporão mediano. Pigídio do macho em forte declive. Quinto urosternito visível suavemente emarginado no macho. Fêmea não conhecida.

Terminália do macho (Figs 11-12). Oitavo tergito arredondado apicalmente, valva ventral com margens laterais côncavas e longas hastes. Lobo médio (Fig. 11) na região basal do saco interno sem escleritos. Região mediana do saco interno com um par de escleritos laminares longos, retos, com região arredondada denticulada subapical. Região apical do saco interno com um esclerito de hastes suavemente separadas apicalmente. Saco interno sem dentículos adensados. Tégmen (Fig. 12) com suave emarginação aguda entre os alargados lobos laterais.

Discussão taxonômica. As duas espécies aqui descritas, A. taeniopygus sp.n. e A. crassipunctatus sp.n., mais Amblycerus insuturatus (Pic, 1902) são relacionadas tendo os seguintes caracteres em comum: mesma coloração de tegumento e pilosidade no pronoto e nos élitros, presença de linha vertical mediana de pêlos adensados no pigídio e escutelo alongado, com ápice tridenteado. Amblycerus taeniopygus sp.n. e $A$. insuturatus têm em comum os escleritos laminares do saco interno do macho com formas assemelhadas e não apresentam pontos grossos na região mediana do pronoto. 


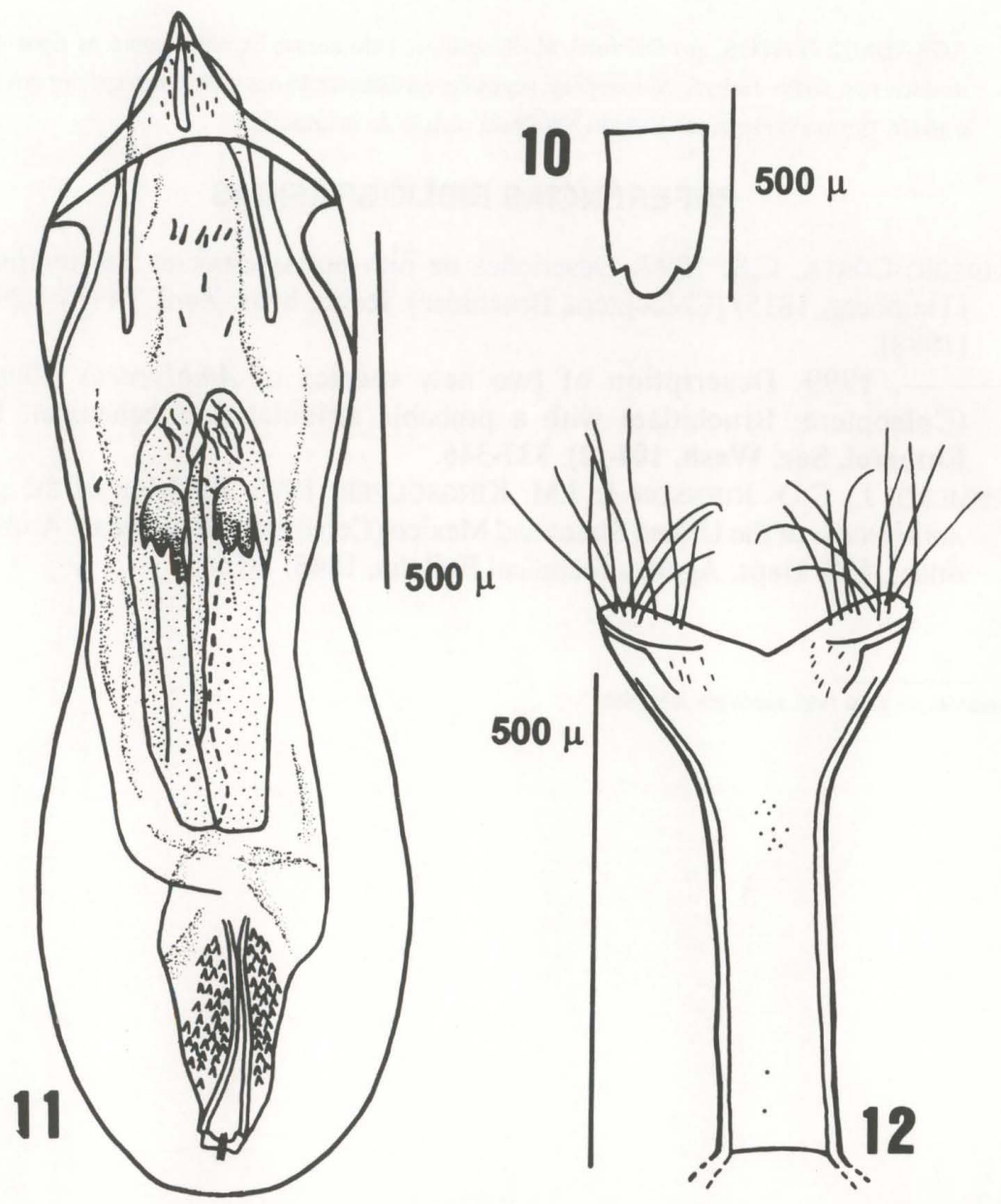

Figs 10-12. Amblycerus taeniopygus sp.n.. (10) Escutelo; (11-12) terminália do macho: (11) lobo médio; (12) tégmen. (EP) Esclerito posterior, (EI) esclerito ímpar, (EL) esclerito laminar, (EA) esclerito apical.

Dentre os grupos de espécies de Amblycerus estabelecidos por ROMERO et al. (1996) observa-se que A. taeniopygus sp.n., A. crassipunctatus sp.n. e $A$. insuturatus aproximam-se dos grupos alternatus e spondiae, que segundo os autores são grupos afins.

Material-tipo. Holótipo macho. BRASIL, Mato Grosso: Cuiabá, L.J. Bottimer Collection, N ${ }^{\circ} 61 \mathrm{C}$; trata-se de um exemplar sem data, depositado na Canadian National Collection of Insects (Ottawa) (CNCI).

Etimologia. O nome da espécie refere-se a presença, no pigídio, de uma faixa vertical mediana de pêlos adensados. 
AGRADECIMENTOS. Ao Dr. John M. Kingsolver pelo acesso às notas sobre os tipos de Amblycerus, ao Pe. Jesus S. Moure pelas sugestões na elaboração dos nomes de espécies novas e ao Dr. Germano Henrique Rosado Neto pela revisão do manuscrito.

\section{REFERÊNCIAS BIBLIOGRÁFICAS}

Ribeiro-Costa, C.S. 1997. Descrições de oito novas espécies de Amblycerus (Thunberg, 1815) (Coleoptera, Bruchidae). Revta bras. Zool. 14 (3): 629-648 [1998].

. 1999. Description of two new species of Amblycerus Thunberg (Coleoptera: Bruchidae) with a probable stridulatory mechanism. Proc. Entomol. Soc. Wash. 101 (2): 337-346.

ROMERO, J.; C.D. JOHNSON \& J.M. KINGSOLVER. 1996. Revision of the genus Amblycerus of the United States and Mexico (Coleoptera: Bruchidae: Amblycerinae). U.S. Dept. Agric., Technical Bulletin, 1845: 1-166.

Recebido em 12.XI.1998; aceito em 19.V.1999. 